\title{
ELENA FORTÚN Y EL GRUPO DE ALUMNAS DE BIBLIOTECONOMÍA DE LA RESIDENCIA DE SEÑORITAS (1930-1936)
}

\author{
Elena Fortún and the Residencia de Señoritas Librarianship Group \\ (1930-1936)
}

\section{Elvira M. Melián*}

Fecha de recepción: 07/03/2017 • Fecha de aceptación: 30/08/2017

Resumen. Los estudios de Biblioteconomía de la Residencia de Señoritas, desarrollados entre 1930 y 1936 bajo los auspicios de Instituto Internacional de Boston, formaron parte de los primeros esfuerzos pedagógicos en favor de la integración laboral femenina en nuestro país. Liderados por María de Maeztu en ellos participaron, además de Elena Fortún, un colectivo de mujeres hoy anónimas que, presumiblemente, encauzaron en este empeño gran parte de sus expectativas. En este trabajo analizamos sus fichas de ingreso y los testimonios dejados por Elena Fortún sobre esta actividad, con el fin de recuperar el perfil humano o, lo que es lo mismo, la intrahistoria de una pionera una iniciativa socio-pedagógica cercenada por la Guerra Civil y su ulterior desenlace.

Palabras clave: Biblioteconomía; Residencia de Señoritas; Elena Fortún; María de Maeztu; Educación de la mujer.

Abstract. The librarianship studies, developed under the auspices of the Boston International Institute by the "Residencia de Señoritas» between 1930 and 1936, were part of the first educational initiatives taken to promote the integration of women into the labour force of Spain. These studies were led by Maria de Maeztu. Along with significant figures like Elena Fortún, a huge collective of anonymous students participated and deposited in this enterprise their important personal prospects. In this work we have investigated the information included in their registration forms as well as Elena Fortun's testimony regarding this activity. We have attempted to recover the human spirit or, in other words, the inside history of this pioneering effort, truncated by the Civil War and its final outcome.

\footnotetext{
"Servicio de Endocrinología y Nutrición. Hospital Universitario La Paz, P. ${ }^{\circ}$ de la Castellana, 261 28046. España.emelian@telefonica.net
} 
Keywords: Librarianship Studies; Residencia de Señoritas; Elena Fortún; María de Maeztu; Women's education.

«Es masa porque no le habéis enseñado a leer» ${ }^{1}$

\section{INTRODUCCIÓN}

En documentos de 1930 conservados en la carpeta de Biblioteconomía del Archivo de la Residencia de Señoritas (ARS) encontramos esbozada la idea de su directora, María de Maeztu, de desarrollar

un curso teórico práctico y gratuito donde las alumnas reciben preparación en catalogación, clasificación, bibliografía, psicología del público, préstamo de libro, bibliotecas populares, bibliotecas circulantes y bibliotecas para niños entre otros. ${ }^{2}$

En la prensa se anunciaba su carácter gratuito, la enseñanza de un idioma adicional gracias a la generosidad del Instituto Internacional de Boston que costeaba a las profesoras, y la entrega de un diploma al finalizar, carente de otro valor adicional al "prestigio de la propia Residencia». ${ }^{3}$ En carta del 13 de noviembre de dicho año María de Maeztu desarrollaba la idea de unas enseñanzas que

consistirán en las siguientes materias: 1, estudio de clasificación de libros según el sistema decimal 2, catalogación alfabética y 3 , conferencias sobre la marcha de la Biblioteca que versarán sobre los temas siguientes. Psicología del público-Clasificación y disposición de los libros-funcionamiento de la Biblioteca-Seminarios de trabajo- Diversas maneras de préstamo de libros- Relación del bibliotecario con el lector- Orientación que éste ha de recibir so-

\footnotetext{
${ }^{1}$ Elena Fortún, Celia en la Revolución (Madrid: Aguilar, 1987), 51.

${ }^{2}$ Archivo Residencia de Señoritas (ARS) de la Fundación Ortega y Gasset-Gregorio Marañon Madrid: Caja 4: Biblioteca (Constituciones, reglamentos y libros pedidos); Caja 13: Alumnas matriculadas en Biblioteconomía, exámenes y fichas.

En la Correspondencia de María de Maeztu, carpetas 30 y 31 aparecen numerosas cartas sobre el proyecto. Sobre la organización del Archivo, consultar María Adelina Codina Canet, «Fuentes Documentales y Archivos de la Residencia de Señoritas de Madrid (1915-1936)", Revista General de Información y Documentación, 25 (2), (2015): 493-515.

3 «La enseñanza y los escolares. Curso de Biblioteconomía en la Residencia de Señoritas», $A B C$ (Madrid), 18 de septiembre de 1933 .
} 
bre los libros que necesita para un estudio determinado- Bibliotecas populares- Bibliotecas para niños- Bibliotecas Circulantes. Todas estas lecciones serán teórico-prácticas. ${ }^{4}$

Nos encontrábamos en la década de los 30 y, gracias a una camaleónica capacidad para transitar entre notables vaivenes sociopolíticos, María de Maeztu se había mantenido como rostro femenino de la Junta de Ampliación de Estudios (JAE) y todopoderosa directora de la Residencia de Señoritas desde su creación en 1915..$^{5}$ Tras un largo periodo como centro de referencia y apoyo para estudiantes de educación superior, la Residencia estaba recuperando su objetivo pedagógico original de «completar la cultura sin designio de obtener título ni abrazar la profesión», contexto en el que debemos contemplar tanto los estudios de Biblioteconomía como los de Música y Coros, en cuyo alumnado predominaron las jóvenes con «cultura general». ${ }^{6}$

Conforme a la naturaleza eminentemente pragmática de su creadora, se trataba de unas enseñanzas orientadas por partes iguales a instruir a las alumnas y favorecer su incorporación al mercado laboral, enmarcadas en el proceso de feminización de la profesión bibliotecaria impulsado desde Estados Unidos durante el último tercio del XIX y el primero del xx. ${ }^{7}$ No en vano, si bien la estructura formal de los estudios a lo largo de dos años se definió el curso 1930-1931, en su base encontramos el breve cursillo de Biblioteconomía que dirigió la norteamericana Mauda Polley del Instituto Internacional de Boston el curso 1928-1929, a raíz de la fusión entre las bibliotecas del mismo y de la Residencia. ${ }^{8}$

\footnotetext{
${ }^{4}$ ARS/ Caja 4, Biblioteca (Constituciones, reglamentos y libros pedidos).

${ }^{5}$ Raquel Vázquez Ramil, Mujeres y educación en la España Contemporánea. La Institución Libre de Enseñanza y la Residencia de Señoritas de Madrid (Madrid: Akal, 2012).

${ }^{6}$ Estas alumnas carecían de titulaciones oficiales de cualquier grado. Sobre estos estudios ver Elvira M. Melián «María de Maeztu Withney y Sofía Novoa Ortiz (1919-1936), cultivar la salud, cultivar el espíritu, cultivar la lealtad», Circunstancia: Revista de Ciencias Sociales del Instituto Universitario de Investigación Ortega y Gasset, 14 (2007). www.fog.es/circunstancia/numero14/art7.

${ }^{7}$ Alba Rodríguez Tojas, «Mujeres y trabajo: la feminización de la profesión bibliotecaria».TFM_Alba_Rod_Toajas_MASTER_ESTUDIOS_FEMINISTAS.pdf (2013), consultado el 11/11/2016, https:// www.ucm.es/data/cont/docs/329-2013-12-17-.

${ }^{8}$ Isabel Pérez- Villanueva Tovar, La Residencia de Estudiantes 1910-1936. Grupo Universitario y Residencia de Señoritas (Madrid: CSIC, 2011).
} 
En nuestras fronteras el antecedente fundamental para los estudios de Biblioteconomía fue la creación por la Mancomunidad de Cataluña en 1915 de la Escola de Bibliotecàries, una escuela exclusivamente femenina destinada a preparar a las mujeres que trabajaron posteriormente en las Bibliotecas Populares de la red establecida por dicha entidad. Si bien las licenciadas en Filosofía y Letras podían aspirar a las plazas de Archiveros y Bibliotecarios desde 1900, la creación de esta y otras carreras «femeninas» de perfil medio permitió por primera vez a muchas mujeres aspirar a una vida profesional más allá del matrimonio y la maternidad. ${ }^{9}$ Ese fue el caso de Encarnación de los Aragoneses Urquijo, más conocida como Elena Fortún, inscrita en los estudios de Biblioteconomía el año de 1932-33, curso académico con mayor número de alumnas y de mayor nivel educativo.

Ya relacionada con María de Maeztu por otras iniciativas, ${ }^{10}$ Elena contaba por entonces 44 años y cierto renombre por sus actividades periodísticas, ${ }^{11}$ y representó un perfil minoritario en el colectivo de alumnas de Biblioteconomía. Carente de titulaciones oficiales, se matriculó entusiasta en unos estudios que le permitían combinar sus investigaciones sobre la historia del cuento con actividades como la Biblioteca Circulante organizada por la Asociación Libros, ${ }^{12}$ una modesta reproducción de las Bibliotecas Populares de las Misiones Pedagógicas, ambicioso proyecto educativo de la República. ${ }^{13}$

Si bien en los fondos digitalizados de la JAE encontramos una breve memoria de esta actividad docente, ${ }^{14}$ hasta ahora no se han examinado individualmente las fichas de las alumnas inscritas en primer curso entre los años académicos 1930-1931 a 1934-1935, último registrado. De este periodo se conservan 224 cuestionarios de ingreso donde se recogen variables como edad, lugar de nacimiento, nivel de estudios, conocimiento de idiomas, conocimiento de taquigrafía y/o mecanografía, lugares a los que se ha viajado, experiencia en bibliotecas, experiencia profesional, y recomendaciones presentadas para acceder a los mismos, en su caso.

\footnotetext{
${ }^{9}$ Rodríguez Tojas, «Mujeres y trabajo», 35.

${ }^{10}$ Marisol Dorao, Los mil sueños de Elena Fortún (Cádiz: Universidad de Cádiz, 1999).

${ }^{11}$ María Jesús Fraga Fernández, Elena Fortún, periodista (Madrid: Pliegos, 2013).

${ }^{12}$ Elvira M. Melián, «Memorias de la Penumbra: Carmen Baroja, Zenobia Camprubí y Elena Fortún, mujeres en la penumbra del 98», Boletín Institución Libre de Enseñanza, 5 (2005): 19-39. Memorias de la JAE, http://archivojae.edaddeplata.org/jae_app., pp. 345-346.

${ }^{13}$ Varios Autores, Las Misiones Pedagógicas 1931-1936 (Madrid: Residencia de Estudiantes, 2007).

${ }^{14}$ Memorias de la JAE, http://archivojae.edaddeplata.org/jae_app.
} 
En este trabajo se ha analizado, por un lado, la información recogida en las fichas de ingreso y, por otro, los testimonios de Elena Fortún sobre esta actividad, con el objeto de recuperar la intrahistoria de una escasamente conocida iniciativa pedagógica, y vincularla con su marco histórico. Con estos elementos se han reunido los datos concretos de las 116 alumnas susceptibles de posterior rastreo individual, por haber obtenido una titulación estatal y/o haber trabajado en organismos oficiales. Pero sobre todo se ha pretendido dibujar el perfil colectivo de unas mujeres, hoy oscuras, que se aferraron a esta empresa para hacer realidad sus anhelos de superación.

\section{RADIOGRAFÍA DE LAS 224 ALUMNAS DE BIBLIOTECONOMÍA} DE LA RESIDENCIA DE SEÑORITAS ENTRE LOS CURSOS 1930-1932

\section{A 1934-1935}

Prototipo de cuestionario de ingreso y sinopsis de las características de las 224 alumnas matriculadas en primer curso a lo largo del tiempo

Tabla 1. Características de las alumnas matriculadas tomando como 100\% de cada curso académico el número total de fichas. (Elaboración propia)

\begin{tabular}{|l|c|c|c|c|c|}
\hline \multicolumn{1}{|c|}{ CURSO ACADÉMICO } & 1930-1931 & 1931-1932 & 1932-1933 & 1933-1934 & 1934-1935 \\
\hline $\begin{array}{l}\text { N. }{ }^{\circ} \text { total de fichas de } \\
\text { matrícula en primer curso }\end{array}$ & 40 & 42 & 61 & 32 & 49 \\
\hline $\begin{array}{l}\text { Edad media de las alumnas } \\
\text { (años) }\end{array}$ & 27 & 27 & 24 & 27 & 26 \\
\hline Origen español (\% del total) & 87 & 93 & 94 & 95 & No consta \\
\hline $\begin{array}{l}\text { Alumnas con viajes previos } \\
\text { al extranjero (\% del total) }\end{array}$ & 35 & 31 & 26 & 26 & 24 \\
\hline $\begin{array}{l}\text { Alumnas con Idiomas, con o } \\
\text { sin diccionario (\% del total) }\end{array}$ & 80 & 71 & 77 & 55 & 52 \\
\hline $\begin{array}{l}\text { Conocimientos de } \\
\text { Taquigrafía/mecanografía } \\
\text { (\% del total de matriculadas) } \\
\text { *Exclusivamente } \\
\text { mecanografía } \\
* \text { Con taquigrafía }\end{array}$ & 25 & 36 & 47 & 61 & 34 \\
\hline $\begin{array}{l}\text { Alumnas con } \\
\text { recomendación (\% del total) }\end{array}$ & 20 & 5 & 5 & 5 & 16 \\
\hline $\begin{array}{l}\text { Alumnas con experiencia } \\
\text { laboral presente o pasada } \\
\text { (\% del total) }\end{array}$ & 47 & 26 & 25 & 34 & 39 \\
\hline
\end{tabular}


La ficha de Elena Fortún que se adjunta como prototipo en el anexo $1^{15}$ indica que inició los estudios de Biblioteconomía el curso académico 1932-1933, en compañía de otras 59 alumnas con edades entre 16 y 36 años, predominantemente españolas (94\%) (Tabla 1). Este perfil se mantuvo relativamente estable desde 1930-1931 hasta 1934-1935. ${ }^{16}$

Como se muestra en la Tabla 1, existió un descenso porcentual progresivo de las alumnas con viajes al extranjero (35-31-26-26-24\%) y las alumnas con manejo de idiomas (80-71-77-55-52\%). El idioma dominante con gran diferencia fue el francés $(>90 \%)$, con o sin asociación con el inglés. Asimismo, disminuyeron las alumnas de provincias en favor de las locales (25-15-9-10-no consta\%, datos no mostrados).

Respecto a 1930-1931 se produjo un descenso abrupto del porcentaje de alumnas recomendadas (20-5-5-5-0\%) (Tabla 1). Desde un punto de vista cualitativo el primer año varias alumnas presentaron referencias de Ortega o Américo Castro, entre otras personalidades, restringiéndose posteriormente las recomendaciones a María de Maeztu y su entorno inmediato.

\footnotetext{
${ }^{15}$ ARS/ Caja 13, carpeta 3/19.

${ }^{16}$ En lo sucesivo los porcentajes se expresan para, respectivamente, los cursos 1930-31, 1931-32, 1932-33, 1933-34 y 1934-35, salvo que se especifique lo contrario. Los porcentajes resultantes de las medias se redondearon arbitrariamente al valor unitario inferior si fueron menores o iguales al decimal 50\%, y al superior en el caso de que fueran mayores al decimal 50\%. Por ejemplo, entre 43 y $44 \%$ se equipararon al $43 \%$ valores entre 43 y $43,5 \%$, y al $44 \%$ valores superiores. Ello explica que en algún caso aislado el total no sea 100\% sino 99 o 101\%, sin que cambie cualitativamente el valor de los datos.
} 


\section{Relación nominal y datos de las 116 alumnas con titulación oficial y/o experiencia laboral en organismos oficiales y/u otras entidades}

Tabla 2. Relación nominal de alumnas de Biblioteconomía con título y/o experiencia laboral en organismos oficiales. Elaboración Propia

\begin{tabular}{|c|c|c|c|c|}
\hline & Nac. & Estudios & Experiencia laboral & $\begin{array}{c}\text { Trabajos } \\
\text { posteriores } \\
\text { (otras fuentes) }\end{array}$ \\
\hline \multicolumn{5}{|c|}{ Curso 1930-1931 } \\
\hline $\begin{array}{l}\text { Carmen Nieto } \\
\text { González } \\
\text { R, 1921-1935 }\end{array}$ & 1900 & $\begin{array}{l}\text { Filosofía y Letras / } \\
\text { Magisterio } \\
\text { Especialidad Archivos } \\
\text { y Bibliotecas }\end{array}$ & $\begin{array}{l}\text { Biblioteca Residencia con } \\
\text { M. Polley/ Clases Licenciatura } \\
\text { y Magisterio }{ }^{1}\end{array}$ & \\
\hline $\begin{array}{l}\text { Matilde López } \\
\text { Serrano } \\
\text { R, 1919-1928 }\end{array}$ & 1899 & Filosofía y letras & $\begin{array}{l}\text { Experiencia como bibliotecaria } \\
\text { que no especifica } \\
\text { Recomendación Eulalia } \\
\text { Lapresta } \\
\end{array}$ & $\begin{array}{l}\text { Directora Biblioteca } \\
\text { Palacio Real }\end{array}$ \\
\hline $\begin{array}{l}\text { Ana García } \\
\text { González }\end{array}$ & 1901 & $\begin{array}{l}\text { Filosofía y Letras / } \\
\text { Magisterio }\end{array}$ & $\begin{array}{l}\text { Bibliotecas Escuela Nacional } \\
\text { de Maestras/ Administración } \\
\text { Colegio en Calle Torcuato } 6\end{array}$ & \\
\hline $\begin{array}{l}\text { María Antonia } \\
\text { Suau Mercadal } \\
\text { R, 1930-1936 }\end{array}$ & 1908 & Filosofía y Letras & $\begin{array}{l}\text { Investigaciones Propias } \\
\text { Instituto Ramón Lull/ } \\
\text { Docencia Instituto Nacional de } \\
\text { Palma }\end{array}$ & $\begin{array}{l}\text { Docencia Instituto- } \\
\text { Escuela }\end{array}$ \\
\hline $\begin{array}{l}\text { María del Pilar } \\
\text { Valdés }\end{array}$ & 1905 & Magisterio & $\begin{array}{l}\text { Enseñanza Escuelas Normales } \\
\text { Carcasona Francia }\end{array}$ & \\
\hline $\begin{array}{l}\text { María Domínguez } \\
\text { López }\end{array}$ & 1907 & Magisterio & Grupo Escolar Cervantes ILE & \\
\hline $\begin{array}{l}\text { Luisa Rúa Figueroa } \\
\text { y Pérez }\end{array}$ & 1907 & Magisterio & $\begin{array}{l}\text { Docencia Prácticas de } \\
\text { Magisterio }\end{array}$ & \\
\hline $\begin{array}{l}\text { Pilar Gavilán } \\
\text { Martín }\end{array}$ & 1907 & Magisterio & $\begin{array}{l}\text { Clases en Escuela Privada de } \\
\text { Durango }\end{array}$ & \\
\hline $\begin{array}{l}\text { Francisca Martínez } \\
\text { Villonas }\end{array}$ & 1910 & Magisterio & $\begin{array}{l}\text { Bibliotecas ILE y Escuela } \\
\text { Normal }\end{array}$ & \\
\hline Teresa Torres & 1902 & Magisterio & $\begin{array}{l}\text { Docencia ILE Historia y } \\
\text { Segunda Enseñanza }^{2}\end{array}$ & $\begin{array}{l}\text { Colonias de } \\
\text { Vacaciones }^{2}\end{array}$ \\
\hline $\begin{array}{l}\text { Dolores Castillo del } \\
\text { Polo }\end{array}$ & & $\begin{array}{l}\text { Auxiliar primera clase } \\
\text { Cuerpo General de } \\
\text { Hacienda Pública }\end{array}$ & $\begin{array}{l}\text { Docencia Párvulos ILE/ } \\
\text { Secretaria Revista Occidente } \\
\text { Recomendación Ortega y } \\
\text { Gasset y Pi Margal (OP) } \\
\end{array}$ & \\
\hline $\begin{array}{l}\text { Regina García } \\
\text { García }\end{array}$ & 1900 & Magisterio & $\begin{array}{l}\text { Periodista en «la mayor parte» } \\
\text { de periódicos Españoles e } \\
\text { Iberoamericanos }\end{array}$ & \\
\hline $\begin{array}{l}\text { Cristina Ferrán } \\
\text { Barrios }\end{array}$ & 1902 & Taquimecanografía & $\begin{array}{l}\text { Bibliotecas Particulares de } \\
\text { Francia }\end{array}$ & \\
\hline $\begin{array}{l}\text { Asunción Pardo } \\
\text { ¿Banzo? }\end{array}$ & 1900 & Profesora Mercantil & $\begin{array}{l}\text { Biblioteca Colegio Nacional de } \\
\text { Huérfanos }\end{array}$ & \\
\hline
\end{tabular}




\begin{tabular}{|c|c|c|c|c|}
\hline & Nac. & Estudios & Experiencia laboral & $\begin{array}{c}\text { Trabajos } \\
\text { posteriores } \\
\text { (otras fuentes) }\end{array}$ \\
\hline $\begin{array}{l}\text { Isabel Rodríguez } \\
\text { Sánchez }\end{array}$ & 1898 & $\begin{array}{l}\text { Título Pinturas y } \\
\text { Grabados Escuela San } \\
\text { Fernando }\end{array}$ & $\begin{array}{l}\text { Clases de dibujo en el Instituto } \\
\text { Internacional }\end{array}$ & \\
\hline $\begin{array}{l}\text { Pilar García } \\
\text { Estirado }\end{array}$ & 1904 & Bachiller & $\begin{array}{l}\text { Secretaria y Bibliotecaria } \\
\text { Editorial Voluntad }\end{array}$ & \\
\hline $\begin{array}{l}\text { Adelina Gurrea } \\
\text { Monasterio }\end{array}$ & 1896 & $\begin{array}{l}\text { High School } \\
\text { (Bachiller) }\end{array}$ & $\begin{array}{l}\text { Dirección Sección Femenina } \\
\text { La Vanguardia Manila }\end{array}$ & Escritora $^{3}$ \\
\hline $\begin{array}{l}\text { Matilde Victoria } \\
\text { Luna }\end{array}$ & & Cultura general & $\begin{array}{l}\text { Auxiliar administrativa Revista } \\
\text { Occidente. Recomendación } \\
\text { Ortega y Gasset }\end{array}$ & \\
\hline $\begin{array}{l}\text { María Martos de } \\
\text { Baeza }\end{array}$ & 1890 & Cultura general & $\begin{array}{l}\text { Biblioteca del Lyceum Club } \\
\text { Recomendaciones María } \\
\text { Maeztu e Isabel Oyarzabal }\end{array}$ & \\
\hline $\begin{array}{l}\text { Emilia Guillaume } \\
\text { Pérez } \\
\text { R, 1930-1931 }\end{array}$ & 1906 & $\begin{array}{l}\text { Filosofía y Letras } \\
\text { (premio } \\
\text { extraordinario) }\end{array}$ & $\begin{array}{l}\text { No experiencia laboral } \\
\text { Investigadora Centro Estudios } \\
\text { Históricos. Recomendación } \\
\text { Américo Castro }\end{array}$ & $\begin{array}{l}\text { Profesora Instituto } \\
\text { Padre Isla, León }{ }^{1}\end{array}$ \\
\hline Mercedes Prieto & 1908 & Filosofía y Letras & $\begin{array}{l}\text { No experiencia laboral } \\
\text { Investigaciones propias cantos } \\
\text { populares y folklorismo } \\
\text { Recomendación Américo } \\
\text { Castro } \\
\end{array}$ & \\
\hline \multicolumn{5}{|c|}{ Curso 1931-1932 } \\
\hline $\begin{array}{l}\text { Luisa Cruces } \\
\text { Matesanz }\end{array}$ & 1891 & Farmacia/Magisterio & Docencia: no especifica lugar ${ }^{5}$ & \\
\hline Isabel Calvo & 1905 & Magisterio & $\begin{array}{l}\text { Biblioteca Instituto Geográfico } \\
\text { Catastral y de Estadística }\end{array}$ & \\
\hline $\begin{array}{l}\text { Marta Cejudo } \\
\text { Hervás } \\
\text { R, 1918-1921 }\end{array}$ & 1900 & Magisterio & $\begin{array}{l}\text { Docencia sección preparatoria } \\
\text { ILE }^{1} \\
\text { Bibliotecas Circulantes } \\
\text { Recomendaciones María de } \\
\text { Maeztu }\end{array}$ & \\
\hline $\begin{array}{l}\text { María Luisa } \\
\text { Retortillo }\end{array}$ & 1902 & Magisterio & Biblioteca de Escuela Normal & \\
\hline $\begin{array}{l}\text { Julia Rodríguez de } \\
\text { Mata } \\
\text { R,1931-1932 }\end{array}$ & 1909 & Magisterio & $\begin{array}{l}\text { Docencia como Auxiliar en la } \\
\text { Escuela Nacional }^{1}\end{array}$ & $\begin{array}{l}\text { Docencia Instituto- } \\
\text { Escuela }\end{array}$ \\
\hline $\begin{array}{l}\text { Adela Rodríguez de } \\
\text { Mata }\end{array}$ & 1900 & $\begin{array}{l}\text { Magisterio/ Institutriz } \\
\text { en Asociación } \\
\text { Enseñanza Mujer/ } \\
\text { Carrera Composición } \\
\text { y Armonía }\end{array}$ & Biblioteca Escuela Normal & \\
\hline $\begin{array}{l}\text { Rosa Domingo } \\
\text { Fernández }\end{array}$ & 1908 & $\begin{array}{l}\text { Magisterio/ } \\
\text { Puericultura / } \\
\text { Taquimecanografía }\end{array}$ & Docencia, pero no especifica & \\
\hline
\end{tabular}




\begin{tabular}{|c|c|c|c|c|}
\hline & Nac. & Estudios & Experiencia laboral & $\begin{array}{c}\text { Trabajos } \\
\text { posteriores } \\
\text { (otras fuentes) }\end{array}$ \\
\hline Matilde García Tros & 1896 & Comercio & $\begin{array}{l}\text { Ministerio de la Gobernación } \\
\text { (OP) }\end{array}$ & \\
\hline Clara Pavón & 1898 & Cultura general & Correos $(\mathrm{OP})$ & \\
\hline $\begin{array}{l}\text { María Santaella } \\
\text { Salas }\end{array}$ & 1905 & Cultura general & Correos (OP) & \\
\hline Eugenia de la Vega & 1909 & Perito Mercantil & $\begin{array}{l}\text { Biblioteca Fundación Eugenio } \\
\text { Trias }\end{array}$ & \\
\hline $\begin{array}{l}\text { Ángela Figuera } \\
\text { ¿Hainmerich? }\end{array}$ & 1912 & Filosofía y Letras & Sin experiencia & \\
\hline Rita María Troyano & 1906 & Magisterio & Sin experiencia & \\
\hline Pilar Torres Negrín & 1989 & Magisterio & Sin experiencia & \\
\hline $\begin{array}{l}\text { María Luisa Gómez } \\
\text { ¿Cecilda? }\end{array}$ & 1903 & $\begin{array}{l}\text { Instrucción } \\
\text { Burocrática Mujeres } \\
\text { Españolas }\end{array}$ & Sin experiencia & \\
\hline $\begin{array}{l}\text { Fraternidad } \\
\text { González }\end{array}$ & 1915 & Comercio & Sin experiencia & \\
\hline $\begin{array}{l}\text { Carmen Rodríguez } \\
\text { Hervás }\end{array}$ & 1901 & Comercio & Sin experiencia & \\
\hline Matilde García Tros & 1896 & Comercio & Sin experiencia & \\
\hline $\begin{array}{l}\text { Pillar Cancellas } \\
\text { Valido }\end{array}$ & 1895 & Contabilidad & Sin experiencia & \\
\hline \multicolumn{5}{|c|}{ Curso 1932-1933 } \\
\hline $\begin{array}{l}\text { María Antonia } \\
\text { Merino } \\
\text { R, 1929-1933 } \\
\end{array}$ & \begin{tabular}{c|}
1907 o \\
1904
\end{tabular} & $\begin{array}{l}\text { Filosofía y Letras/ } \\
\text { Magisterio }\end{array}$ & Biblioteca Universitaria & $\begin{array}{l}\begin{array}{l}\text { Clases Instituto } \\
\text { Carmona de Sevilla } \\
\text { (depurada) }^{1}\end{array} \\
\end{array}$ \\
\hline $\begin{array}{l}\text { María Luisa } \\
\text { Mellado Calvo } \\
\text { R, 1921-1924; } \\
1929-1933\end{array}$ & & $\begin{array}{l}\text { Filosofía y Letras/ } \\
\text { Magisterio }\end{array}$ & $\begin{array}{l}\text { Fundadora Bibliotecas } \\
\text { circulante Larache/ Docencia } \\
\text { primaria y secundaria }\end{array}$ & $\begin{array}{l}\text { Directora Escuelas } \\
\text { Españolas Larache }^{1}\end{array}$ \\
\hline Adela Palacios & 1911 & Filosofía y Letras & $\begin{array}{l}\text { Biblioteca Facultad de } \\
\text { Derecho }\end{array}$ & $\begin{array}{l}\text { Organizadora de la } \\
\text { Asociación de } \\
\text { Bibliotecas y } \\
\text { Biógrafos de } \\
\text { España en } 1934^{2}\end{array}$ \\
\hline $\begin{array}{l}\text { María Josefa } \\
\text { Salvatierra Las } \\
\text { Peñas } \\
\text { R, 1930-1934 } \\
\end{array}$ & 1910 & Filosofía y Letras & $\begin{array}{l}\text { Docencia sin especificar. } \\
\text { Recomendación María de } \\
\text { Maeztu }\end{array}$ & $\begin{array}{l}\text { Profesora de } \\
\text { Instituto }^{1}\end{array}$ \\
\hline \begin{tabular}{|l|} 
Josefa Castán \\
Zuloaga \\
R, 1919-1935 \\
\end{tabular} & & Magisterio & $\begin{array}{l}\text { Profesora Instituto-Escuela. } \\
\text { Recomendación María de } \\
\text { Maeztu }\end{array}$ & \\
\hline $\begin{array}{l}\text { Salvadora Gil Pola } \\
\text { R,1929-1935 }\end{array}$ & 1912 & Magisterio & Docencia sin definir & $\begin{array}{l}\text { Maestra en } \\
\text { Monover, Alicante }^{1}\end{array}$ \\
\hline $\begin{array}{l}\text { María ¿Héctor? } \\
\text { Vázquez }\end{array}$ & & Magisterio & Docencia instituto Sevilla & \\
\hline
\end{tabular}




\begin{tabular}{|c|c|c|c|c|}
\hline & Nac. & Estudios & Experiencia laboral & $\begin{array}{c}\text { Trabajos } \\
\text { posteriores } \\
\text { (otras fuentes) }\end{array}$ \\
\hline $\begin{array}{l}\text { María Josefa Martín } \\
\text { Luque }\end{array}$ & 1899 & Magisterio & $\begin{array}{l}\text { Docencia Escuela de } \\
\text { Sordomudos }\end{array}$ & \\
\hline $\begin{array}{l}\text { Rosalía Martín } \\
\text { Bravo } \\
\text { R, 1923-1928 } \\
\end{array}$ & 1902 & Magisterio & Docencia Instituto-Escuela & \\
\hline $\begin{array}{l}\text { Pilar Montero } \\
\text { Hernández }\end{array}$ & 1907 & Magisterio & $\begin{array}{l}\text { Docencia en ILE y Escuela } \\
\text { Normal Villa del Prado }\end{array}$ & \\
\hline $\begin{array}{l}\text { Mara del Carmen } \\
\text { Navarro Díaz }\end{array}$ & 1913 & Magisterio & Docente Escuela Superior & \\
\hline $\begin{array}{l}\text { María Nogués } \\
\text { Viviella } \\
\text { R, 1926-1928 }\end{array}$ & & Magisterio & $\begin{array}{l}\text { Docente oposición Escuela de } \\
\text { Sordomudos }\end{array}$ & $\begin{array}{l}\text { Escuela Freinet, } \\
\text { Tibidado Barcelona }\end{array}$ \\
\hline $\begin{array}{l}\text { María del Carmen } \\
\text { ¿Lardiez? }\end{array}$ & 1910 & Magisterio & $\begin{array}{l}\text { Docente Escuelas Normales en } \\
\text { Repujados y Esculturas }\end{array}$ & \\
\hline $\begin{array}{l}\text { María Antonia } \\
\text { Corrales y Gallego }\end{array}$ & 1907 & Filosofía y Letras & $\begin{array}{l}\text { Cuerpo de Archiveros y } \\
\text { Bibliotecas Biblioteca } \\
\text { Nacional de Bellas Artes }\end{array}$ & \\
\hline $\begin{array}{l}\text { Filomena } \\
\text { Manzanero García }\end{array}$ & 1899 & Cultura general & Biblioteca del Centro Obrero & \\
\hline $\begin{array}{l}\text { Maruja Blanco } \\
\mathrm{R}, \text { 1931-1935 } \\
\end{array}$ & 1912 & Filosofía y Letras & Sin experiencia & \\
\hline $\begin{array}{l}\text { María Luisa Gil de } \\
\text { Pradilla, } \\
\text { R, 1931-1933 }\end{array}$ & & Filosofía y Letras & Sin experiencia & \\
\hline $\begin{array}{l}\text { María Gloria } \\
\text { Alique Tomico } \\
\text { R, 1931-1932 } \\
\end{array}$ & 1915 & Filosofía y Letras & Sin experiencia & \\
\hline $\begin{array}{l}\text { María Rosario } \\
\text { Iglesias }\end{array}$ & 1912 & Filosofía y Letras & Sin experiencia & \\
\hline Magdalena Iglesias & 1912 & Filosofía y Letras & Sin experiencia & $\begin{array}{l}\text { Evaluadora de } \\
\text { Letras Colegio } \\
\text { Cardenal Cisneros } \\
\text { 1933-1934. } \\
\text { Clases Instituto } \\
\text { Femenino }{ }^{2} \\
\end{array}$ \\
\hline $\begin{array}{l}\text { Enriqueta Jiménez } \\
\text { Ramos } \\
\text { R, 1931-1933 } \\
\end{array}$ & 1909 & $\begin{array}{l}\text { Filosofía y Letras } \\
\text { (Historia) }\end{array}$ & Sin experiencia & \\
\hline $\begin{array}{l}\text { Carmen Jiménez } \\
\text { Ramos } \\
\text { R, 1931-1933 }\end{array}$ & 1911 & $\begin{array}{l}\text { Filosofía y Letras } \\
\text { (Historia) }\end{array}$ & Sin experiencia & \\
\hline $\begin{array}{l}\text { Aurora García } \\
\text { Castilla } \\
\text { R, 1929-1934 }\end{array}$ & 1902 & Filosofía y Letras & $\begin{array}{l}\text { Sin experiencia. } \\
\text { Recomendación María de } \\
\text { Maeztu }\end{array}$ & \\
\hline
\end{tabular}




\begin{tabular}{|c|c|c|c|c|}
\hline & Nac. & Estudios & Experiencia laboral & $\begin{array}{c}\text { Trabajos } \\
\text { posteriores } \\
\text { (otras fuentes) }\end{array}$ \\
\hline $\begin{array}{l}\text { María Teresa Díez } \\
\text { Iglesias } \\
\text { R, 1928-1933 }\end{array}$ & & Filosofía y Letras & $\begin{array}{l}\text { Sin experiencia. } \\
\text { Recomendación María de } \\
\text { Maeztu }\end{array}$ & \\
\hline $\begin{array}{l}\text { Amelia Seco } \\
\text { Carrancia } \\
\text { R, 1930-1935 }\end{array}$ & 1911 & Filosofía y Letras & $\begin{array}{l}\text { Sin experiencia. } \\
\text { Recomendación María de } \\
\text { Maeztu }\end{array}$ & \\
\hline $\begin{array}{l}\text { María de la Villa } \\
\text { Fernández de } \\
\text { Velasco } \\
\text { R, 1931-1936 }\end{array}$ & 1922 & Filosofía y Letras & $\begin{array}{l}\text { Sin experiencia. } \\
\text { Recomendación María de } \\
\text { Maeztu }\end{array}$ & $\begin{array}{l}\text { Ayudante de } \\
\text { Biblioteca } \\
\text { Residencia de } \\
\text { Señoritas/ Clases de } \\
\text { Historia del Arte, } \\
\text { Residencia de } \\
\text { Señoritas }^{1}\end{array}$ \\
\hline $\begin{array}{l}\text { Patrocinio } \\
\text { Rodríguez Márquez }\end{array}$ & 1909 & Farmacia & Sin experiencia & \\
\hline $\begin{array}{l}\text { Cecilia de Barrio } \\
\text { Calvo }\end{array}$ & 1915 & Magisterio & Sin experiencia & \\
\hline $\begin{array}{l}\text { Pilar Jurado } \\
\text { Sánchez } \\
\text { R, 1931-1932 }\end{array}$ & & Magisterio & $\begin{array}{l}\text { Sin experiencia. } \\
\text { Recomendación María de } \\
\text { Maeztu }\end{array}$ & \\
\hline $\begin{array}{l}\text { María Luisa } \\
\text { Sánchez Robledo }\end{array}$ & 1902 & Magisterio & Sin experiencia & \\
\hline Emilia Parrondo & & Comercio & Sin experiencia & \\
\hline Carmen Purcel & & Taquimecanografía & Sin experiencia & \\
\hline $\begin{array}{l}\text { Adela Carranceja y } \\
\text { González }\end{array}$ & & Enfermería & Sin experiencia & $\begin{array}{l}\text { Gaceta Madrid n. }{ }^{\circ} \\
150,30 / 05 / 1934, \mathrm{p} . \\
802\end{array}$ \\
\hline $\begin{array}{l}\text { Carmen Ortigas de } \\
\text { Castro }\end{array}$ & & $\begin{array}{l}\text { Taquimecanografía/ } \\
\text { Comercio }\end{array}$ & Sin experiencia & \\
\hline $\begin{array}{l}* \text { Ernestina de } \\
\text { Champourcin }\end{array}$ & & Bachiller & $\begin{array}{l}\text { Recomendación María de } \\
\text { Maeztu }\end{array}$ & \\
\hline \multicolumn{5}{|c|}{ Curso 1933-1934 } \\
\hline $\begin{array}{l}\text { María Rosa Alonso } \\
\text { Frías }\end{array}$ & 1910 & Filosofía y Letras & $\begin{array}{l}\text { Biblioteca. Fundadora } \\
\text { Instituto Estudio Canarios }\end{array}$ & \\
\hline $\begin{array}{l}\text { Ana María } \\
\text { Rodríguez }\end{array}$ & & Filosofía y Letras & Docencia Instituto Escuela & \\
\hline $\begin{array}{l}\text { Narcisa Villarino } \\
\text { Velázquez }\end{array}$ & 1905 & Magisterio & Profesora en activo & \\
\hline $\begin{array}{l}\text { Encarnación } \\
\text { Marcos Bustamante }\end{array}$ & 1910 & Magisterio & $\begin{array}{l}\text { Clases colegio Brighton, } \\
\text { Inglaterra, 1932-1922 }\end{array}$ & \\
\hline Pilar Devesa & 1906 & Magisterio & Docencia Instituto-Escuela & \\
\hline $\begin{array}{l}\text { Carmen de Mesa } \\
\text { Pérez }\end{array}$ & 1912 & Enfermera & $\begin{array}{l}\text { Biblioteca Laboratorio } \\
\text { Instituto de Biología y } \\
\text { Sueroterapia de Madrid }\end{array}$ & \\
\hline
\end{tabular}




\begin{tabular}{|c|c|c|c|c|}
\hline & Nac. & Estudios & Experiencia laboral & $\begin{array}{c}\text { Trabajos } \\
\text { posteriores } \\
\text { (otras fuentes) }\end{array}$ \\
\hline Carmen Coll & 1890 & Secretariado & $\begin{array}{l}\text { Instituto Español Oceanografía } \\
\text { e Instituto Sanitario (OP) }\end{array}$ & \\
\hline $\begin{array}{l}\text { Concepción Gullón } \\
\text { Rubio }\end{array}$ & 1908 & Taquimecanografía & Ayuntamiento de Madrid (OP) & \\
\hline $\begin{array}{l}\text { Teresa Fernández } \\
\text { de Navas }\end{array}$ & 1907 & $\begin{array}{l}\text { Auxiliar } \\
\text { administrativo }\end{array}$ & $\begin{array}{l}\text { Biblioteca Ministerio de } \\
\text { Marina (OP) }\end{array}$ & \\
\hline Lara del Valle & 1894 & Cultura general & Funcionaria de Hacienda (0P) & \\
\hline $\begin{array}{l}\text { Carmen Leroy } \\
\text { ¿Bartanca? }\end{array}$ & & Cultura general & \begin{tabular}{|l|} 
Biblioteca laboratorio Dr. \\
Negrín \\
\end{tabular} & \\
\hline $\begin{array}{l}\text { ¿Elena? Terra } \\
\text { ¿Álvarez? }\end{array}$ & 1910 & Filosofía y Letras & Sin experiencia & \\
\hline $\begin{array}{l}\text { Vicenta Alonso } \\
\text { Delgado }\end{array}$ & 1902 & Filosofía y Letras & Sin experiencia & $\begin{array}{l}\text { Catedrática } \\
\text { Instituto de Mérida }^{1}\end{array}$ \\
\hline $\begin{array}{l}\text { Isabel López } \\
\text { Ganivet }\end{array}$ & 1905 & Perito Mercantil & Sin experiencia & \\
\hline $\begin{array}{l}\text { Josefa López } \\
\text { Ganivet }\end{array}$ & 1908 & Magisterio & Sin experiencia & \\
\hline $\begin{array}{l}\text { María Luisa } \\
\text { Bencomo Alonso }\end{array}$ & 1914 & Magisterio & Sin experiencia & \\
\hline $\begin{array}{l}\text { Francisca Noriega } \\
\text { Delgado }\end{array}$ & 1904 & Enfermería & Sin experiencia & \\
\hline $\begin{array}{l}\text { María del Carmen } \\
\text { Noriega Delgado }\end{array}$ & 1909 & Enfermería & Sin experiencia & \\
\hline Felipa Albarrán & 1916 & Comercio & Sin experiencia & \\
\hline \multicolumn{5}{|c|}{ Curso 1934-1935 } \\
\hline $\begin{array}{l}\text { Remedios Míguelez } \\
\text { de Mendiluce }\end{array}$ & 1911 & Filosofía y Letras & $\begin{array}{l}\text { Biblioteca Ciudad } \\
\text { Universitaria Madrid } \\
\end{array}$ & \\
\hline $\begin{array}{l}\text { María Pilar } \\
\text { Fernández Casado }\end{array}$ & 1914 & Filosofía y Letras & \begin{tabular}{|l|} 
Enseñanza Centro Obrero / \\
Bibliotecas \\
\end{tabular} & \\
\hline $\begin{array}{l}\text { María del Carmen } \\
\text { Fernández Casado }\end{array}$ & 1913 & Filosofía y Letras & Enseñanza Centro Obrero & \\
\hline $\begin{array}{l}\text { Ana Gasset de las } \\
\text { Moreras }\end{array}$ & 1910 & $\begin{array}{l}\text { Filosofía y Letras/ } \\
\text { Farmacia }\end{array}$ & $\begin{array}{l}\text { Cinco años docencia Sección } \\
\text { juegos Instituto-Escuela }\end{array}$ & \\
\hline $\begin{array}{l}\text { ¿Ramona? Blasco y } \\
\text { Millán }\end{array}$ & 1909 & Magisterio & $\begin{array}{l}\text { Docencia en Escuela Normal y } \\
\text { trabajo en Biblioteca Nacional }\end{array}$ & \\
\hline María Marín Villarte & $19 ?$ & Magisterio & $\begin{array}{l}\text { Experiencia docente sin } \\
\text { especificar }\end{array}$ & \\
\hline $\begin{array}{l}\text { Josefina Rodríguez } \\
\text { Suárez }\end{array}$ & 1900 & Magisterio & $\begin{array}{l}\text { Diez años enseñanza en } \\
\text { primaria y secundaria }\end{array}$ & \\
\hline Pilar Sanz de la Villa & 1912 & Magisterio & $\begin{array}{l}\text { Docencia. Clases en biblioteca } \\
\text { Facultad de Derecho }\end{array}$ & \\
\hline $\begin{array}{l}\text { María Victoria } \\
\text { Marín }\end{array}$ & 1898 & Magisterio/Comercio & $\begin{array}{l}\text { Docencia preparatorio } \\
\text { bachiller y Magisterio sin } \\
\text { especificar }\end{array}$ & \\
\hline
\end{tabular}




\begin{tabular}{|c|c|c|c|c|}
\hline & Nac. & Estudios & Experiencia laboral & $\begin{array}{c}\text { Trabajos } \\
\text { posteriores } \\
\text { (otras fuentes) }\end{array}$ \\
\hline $\begin{array}{l}\text { Adela Martínez } \\
\text { Lacase }\end{array}$ & 1895 & Mecanografía & $\begin{array}{l}\text { Biblioteca Ministerio de la } \\
\text { Marina (OP) }\end{array}$ & \\
\hline $\begin{array}{l}\text { Olimpia Ruiz } \\
\text { Blanco }\end{array}$ & 1915 & Mecanografía & $\begin{array}{l}\text { Ministerio de Marina } \\
\text { Biblioteca Museo Naval (OP) }\end{array}$ & \\
\hline $\begin{array}{l}\text { Matilde Marina y } \\
\text { Crespo }\end{array}$ & 1905 & Cultura general & $\begin{array}{l}\text { Traductora Museo Naval } \\
\text { Ministerio Marina (OP) }\end{array}$ & \\
\hline $\begin{array}{l}\text { Amparo Ordoñez de } \\
\text { Barracuda }\end{array}$ & 1908 & Cultura General & $\begin{array}{l}\text { Secretaria Asociación España- } \\
\text { Filipinas }\end{array}$ & \\
\hline $\begin{array}{l}\text { Cristina Ordóñez de } \\
\text { Barracuda }\end{array}$ & 1915 & Cultura General & $\begin{array}{l}\text { Secretaria Asociación España- } \\
\text { Filipinas }\end{array}$ & \\
\hline $\begin{array}{l}\text { Paquita Serrano } \\
\text { Ruiz }\end{array}$ & 1906 & Auxiliar & $\begin{array}{l}\text { Ministerio Instrucción Pública } \\
\text { (OP) }\end{array}$ & \\
\hline $\begin{array}{l}\text { María Gil } \\
\text { ¿Fonsesoni? }\end{array}$ & 1890 & Cultura general & $\begin{array}{l}\text { Funcionaria Dirección General } \\
\text { Sanidad desde } 1923(\mathrm{OP})\end{array}$ & \\
\hline $\begin{array}{l}\text { María Luisa Luzón } \\
\text { ¿Garrido vs } \\
\text { Carcedo? }\end{array}$ & 1910 & Auxiliar & $\begin{array}{l}\text { Funcionaria Ministerio de la } \\
\text { Gobernación (OP) }\end{array}$ & \\
\hline $\begin{array}{l}\text { María Angulo y } \\
\text { Esteban }\end{array}$ & 1911 & Cultura general & $\begin{array}{l}\text { Auxiliar de catálogos de la } \\
\text { Biblioteca Nacional (OP) }\end{array}$ & \\
\hline $\begin{array}{l}\text { María Dolores } \\
\text { Fernández Casado }\end{array}$ & 1909 & Cultura general & Enseñanza Centro Obrero & \\
\hline $\begin{array}{l}\text { Teresa Díaz de } \\
\text { Diestro }\end{array}$ & 1909 & Puericultura & Sin experiencia & \\
\hline $\begin{array}{l}\text { María del Barrio } \\
\text { Ramos }\end{array}$ & 1909 & Filosofía y Letras & Sin experiencia & \\
\hline $\begin{array}{l}\text { Concepción Isabel } \\
\text { de la Calzada }\end{array}$ & 1908 & Filosofía y Letras & Sin experiencia & \\
\hline
\end{tabular}

Negrita: Alumnas que vivían en la Residencia de Señoritas según Vázquez Ramil. ${ }^{1}$

Notas a la tabla:

* En el curso de 1932-1933 encontramos matriculada a Ernestina de Champourcin. Con título de Bachillerato en el Instituto Cardenal Cisneros y sin trabajo en organismos oficiales en sentido estricto no puede contabilizarse en esta estadística, pero ya empezaba a destacar en los medios literarios y alcanzaría significativa relevancia como poeta.

1 Vázquez Ramil, Mujeres yeducación en la España contemporánea, 373-451

2 Poveda Sanz, Mujeres y Segunda Enseñanza en Madrid (1931-1939). Tesis doctoral. Madrid. Universidad Complutense, 2014.

${ }^{3}$ Andrea Gallo, La herencia hispánica en dos autoras filipinas del siglo XX: Adelina Gurrea Monasterio y Elizabeth Medina (Alicante: Biblioteca Virtual Miguel de Cervantes, 2014).

${ }^{4}$ Melián, «Rastros de nube».

${ }^{5}$ Consuelo Flecha, Las primeras universitarias en España, 1872-1910 (Madrid: Narcea, 1996), 156.

OP: Opositora.¿¿Itálica?: posible inexactitud por dificultad en la lectura de la letra. 
La Tabla 2 recoge los datos de las alumnas que declararon tener títulos oficiales de cualquier grado y/o relación laboral - pasada o presente- con organismos oficiales y, más raramente, empresas. En la última columna se recoge información del destino laboral posterior $u$ otros datos sobre estas alumnas, resultante de un análisis preliminar en otras fuentes.

Se resaltan las alumnas que se alojaban o referían haberse alojado en la Residencia de Señoritas, en su totalidad estudiantes de Magisterio o Licenciatura. Cabe destacar la notoria superioridad porcentual de alumnas con estas características el curso 1932-1933, frente al resto de los cursos académicos.

\section{Nivel educativo de las alumnas matriculadas en primer curso a lo largo del tiempo}

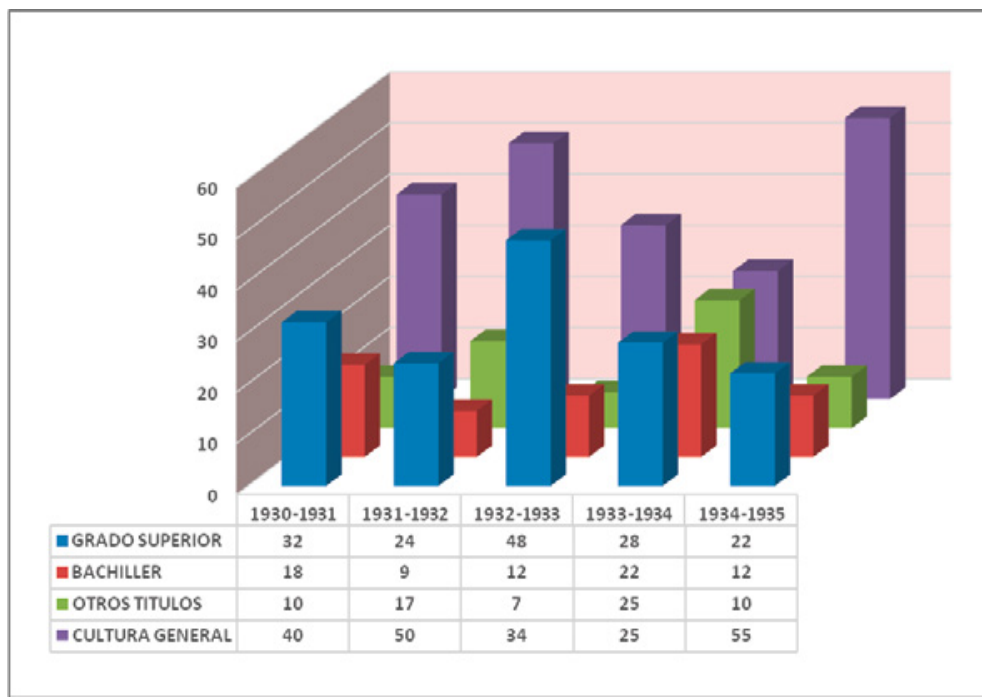

Gráfico 1. Características y evolución del nivel educativo de alumnas tomando como 100\% de cada curso académico el número total de fichas (Elaboración propia).

Para analizar el nivel educativo de las matriculadas se establecieron cuatro subgrupos: (1) superior, donde se sumaron licenciadas y/o maestras dada la superposición de datos en gran parte de los casos, ${ }^{17}$ (2) ba-

\footnotetext{
${ }^{17}$ Se consideró siempre el nivel educativo superior, y las estudiantes matriculadas en tercero- tres casos- se incluyeron como tituladas.
} 
chillerato, (3) otros títulos (comercio, perito mercantil, contabilidad, taquimecanografía, auxiliar administrativo u enfermería), y (4) «cultura general», donde se incluyeron las que específicamente se autodefinieron así y aquellas que no reflejaron estudios oficiales de ningún tipo, incluyendo las alumnas que referían conocimientos de música de ambigua definición. Las licenciadas lo fueron en Filosofía y Letras en prácticamente su totalidad, aunque encontramos dos licenciadas en Farmacia. Se observa un notable y sostenido predominio de alumnas de los subgrupos de cultura general (40-50-34-25-55\%) y grado superior (32-24-48-28-22\%) frente a las bachilleres y de otros grados, con una homogenización relativa el curso 1933-1934 (Gráfico1). Entre los grupos predominantes el curso de 1332-1933 las alumnas de grado superior superaron porcentualmente al subgrupo de cultura general, con un 48 y $34 \%$ del alumnado, respectivamente (Gráfico 1).

\section{Porcentaje de alumnas con experiencia laboral en función de cada nivel educativo entre las matriculadas en primer curso, y perfil evolutivo de actividad laboral}

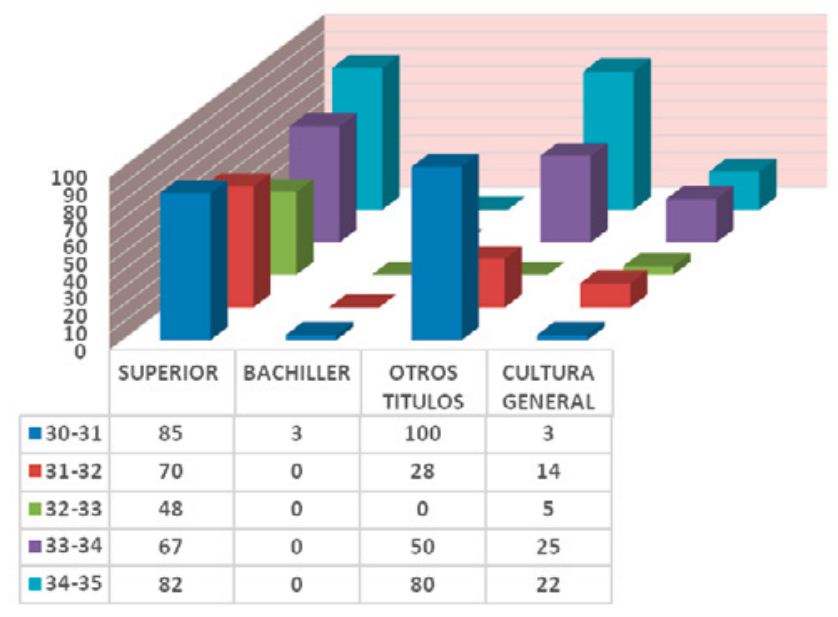

Gráfico 2. Porcentaje y evolución de las alumnas con experiencia laboral por subgrupo educativo tomando como $100 \%$ de cada curso académico el número total de fichas (Elaboración propia).

Para calcular el porcentaje de alumnas son experiencia laboral en el total de matriculadas se contabilizaron los trabajos en bibliotecas, 
institutos, colegios, empresas y otros organismos oficiales "por cuenta ajena», excluyendo las difícilmente valorables clases particulares. Este porcentaje se calculó sin solución de continuidad entre experiencia previa o vigente, dado que el cuestionario de ingreso no establecía una diferenciación específica. Con estos criterios un significativo porcentaje de alumnas afirmaba tener experiencia laboral a lo largo de los cursos registrados (47-26-25-34 y 39\%) (Tabla 1). La correlación con los subgrupos educativos se recoge en el gráfico 2 . Observamos un notable porcentaje de ocupación entre las alumnas de grado superior (85-70-48-67-82\%), seguido por las poseedoras de otros títulos (100-28-0-50 y $80 \%$ y las alumnas con cultura general (3-14-5-25-22\%), ambos grupos con un notorio aumento a partir de 1933-1934. La experiencia laboral en el subgrupo de alumnas con bachillerato fue insignificante.

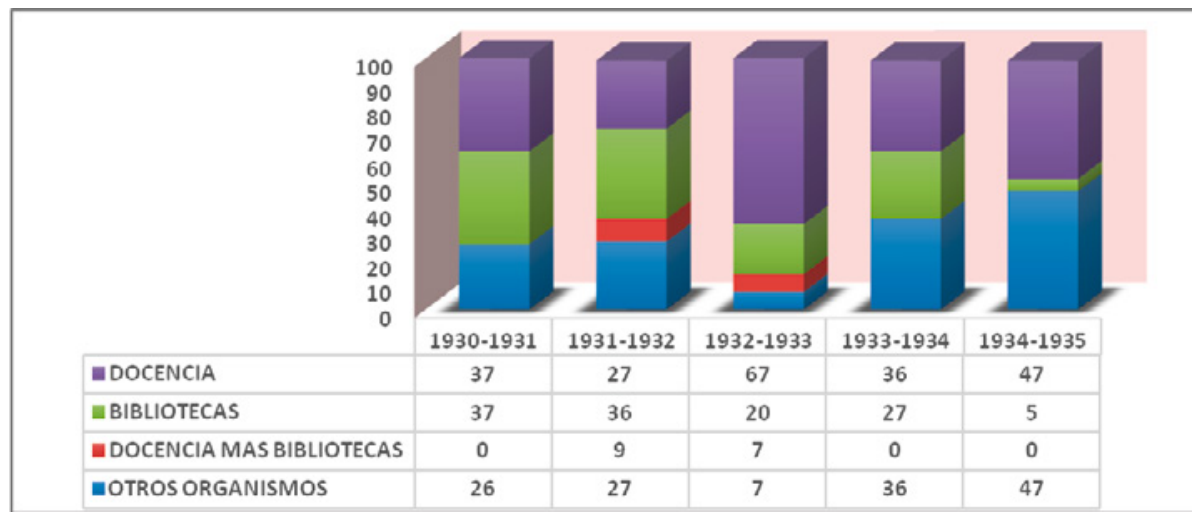

Gráfico 3. Tipo de experiencia laboral en porcentaje tomando como $100 \%$ el total de fichas de alumnas con dicha experiencia (Elaboración propia).

El gráfico 3 muestra el porcentaje de ocupación por subgrupos educativos a lo largo del tiempo. Primó la docencia (37-27-67-36-47\%) seguida por los trabajos en bibliotecas (37-36-20-27-5\%), hasta alcanzar entre ambas actividades en 1932-1933 el 93\% del total de alumnas con experiencia. Sin embargo, a partir de 1933-1934 el trabajo en otros organismos (26-27-7-36-47\%) igualó a la docencia y superó ampliamente a la biblioteconomía. 
Salvando el curso de 1932-1933, asistimos a una gradual incorporación laboral en bibliotecas y/o de organismos públicos de un conjunto de alumnas sin titulación superior, con frecuencia mediante oposiciones (Tabla 2). El curso de 1931-1932 encontramos a la titulada en Comercio Matilde García Tros en el Ministerio de Gobernación, y a Clara Pavón y María Santaella Salas —ambas de cultura general- en Correos. El curso de 1933-1934 Teresa Fernández de Navas, auxiliar administrativa, trabaja en la Biblioteca del Ministerio de Marina; Concepción Gullón Rubio, con Taquimecanografía, ha opositado al Ayuntamiento de Madrid; Carmen Coll, con Secretariado, trabaja en la Biblioteca del Instituto de Oceanografía; la enfermera Carmen de Mesa en el Instituto de Biología y Sueroterapia de Madrid, y dos alumnas con cultura general, Lara del Valle y Carmen Leroy trabajan en Hacienda tras oposición y en la Biblioteca del Laboratorio Negrín, respectivamente. Finalmente, el curso de 1934-1935 encontramos a siete opositoras: las mecanógrafas Olimpia Ruiz Blanco y Adela Martínez, y Matilde Marina y Crespo, con cultura general-, en el Ministerio de Marina; las auxiliares Paquita Serrano Ruiz y María Luisa Luzón en los Ministerios de Instrucción Pública y Gobernación, respectivamente; y María Gil y María Angulo Esteban, ambas de cultura general, en el Ministerio de Sanidad y como Auxiliar de Catálogos en la Biblioteca Nacional. Aunque no se trataba de un organismo oficial en sentido estricto las dos hermanas Ordoñez de Barracuda, con cultura general, eran secretarias en la activa Asociación Cultural España-Filipinas. ${ }^{18}$

Es ilustrativo observar como, de carecer de otras fuentes, Elena Fortún, con un diploma de suficiencia del Centro de Estudios Históricos y experiencia docente particular, se hubiera etiquetado como alumna de cultura general, natural de Madrid, con manejo de idiomas (francés), conocimientos de mecanografía, y no trabajadora. No hubiera aparecido pues en la Tabla 2. De ahí la importancia de subsumir los datos individuales en un análisis colectivo para confrontarlo eficazmente con sus coordenadas históricas.

18 «Defensa del idioma castellano en Filipinas» (Sevilla) $A B C 26$ de agosto de 1934. http://hemeroteca. abc.es/nav/Navigate.exe/hemeroteca/sevilla/abc.sevilla/1934/08/26/022.html. En esta misma fuente se recogen numerosos actos de esta Asociación en estos años. 


\section{ANÁLISIS DEL PERFIL Y CARACTERÍSTICAS COLECTIVAS DEL ALUMNADO DE BIBLIOTECONOMÍA}

Podría considerarse la Residencia de Señoritas como la muestra femenina del ideario educativo de la Institución Libre de Enseñanza (ILE) desplegada por la JAE durante el primer tercio del siglo XX. ${ }^{19}$ La biografía intelectual de su directora, María de Maeztu, admite cientos de trabajos sobre su labor pedagógica. Su interacción con la JAE se inició como becaria (Londres, 1908; Bruselas, Amberes y Zurich, 1910, y Maburgo, 1912-13), para continuar con su designación para cuatro cargos relevantes: Directora de la Residencia de Señoritas, 1916; Presidenta del Instituto Internacional de Señoritas, 1917; Directora del Grupo de Niños de la Sección Preparatoria del Instituto-Escuela, 1918 y, finalmente, vocal de la JAE en 1928, siendo la única mujer que ocupó este cargo. Ya en su madurez, entre 1919 y 1929 la JAE le financió varias estancias EE.UU y América del Sur. ${ }^{20}$

En 1930, primera convocatoria regular de los estudios de Biblioteconomía, María había evolucionado ideológicamente desde un notorio europeísmo ligado a las premisas regeneracionistas a un tradicionalismo católico-hispanista que la llevó a ocupar entre 1928 y 1930, fecha de la caída de Primo de Rivera, una poderosa posición como miembro de la Junta Directiva de la JAE, sustentada en parte sobre la significación de su hermano Ramiro. ${ }^{21} \mathrm{El}$ auge de la Residencia, que condujo a crear de varias Casas y ampliar de la oferta educativa, le permitió interaccionar con los focos de intelectualidad más destacados del primer tercio del siglo Xx. ${ }^{22} \mathrm{Y}$, aunque en esos momentos Maeztu temía represalias por su labor colaboracionista — «no quedan en pie más que los que caminan muy muy hacia la izquierda ${ }^{23}$-, la República siguió favoreciéndola. De hecho el inicio de la Guerra Civil la encontró a la cabeza de su Residen-

\footnotetext{
${ }^{19}$ Carmen de Zulueta, Alicia Moreno, Ni convento ni college. La Residencia de Señoritas (Madrid: Consejo Superior de Investigaciones Científicas, 1993); Vázquez Ramil, Mujeres y educación en la España Contemporánea; Pérez- Villanueva Tovar, La Residencia de Estudiantes 1910-1936.

${ }^{20}$ Isabel Pérez-Villanueva Tovar, María de Maeztu: una mujer en el reformismo educativo español (Madrid: UNED, 1989)

${ }^{21}$ Elvira M. Melián, «En la frontera: señas de identidad de la labor pedagógica hispano-americanista en María de Maeztu (1924-1936)», Historia de la Educación 34 (2015): 287-303.

${ }^{22}$ Melián, «María de Maeztu Withney y Sofía Novoa Ortiz (1919-1936)».

${ }^{23}$ ARS/ Correspondencia María de Maeztu/Notables/ Maeztu a Baeza 15/09/1931.
} 
cia, y felizmente incorporada a la docencia en las cátedras de Pedagogía e Historia de la Pedagogía de la Universidad Central. ${ }^{24}$

Desde el año académico de 1924-1925 hasta 1934-1934 no existieron alumnas residentes dedicadas a adquirir cultura general en una Institución que se definía públicamente como de Educación Superior. ${ }^{25}$ Sin embargo durante la década de los 30 la Residencia aumentó su oferta para este colectivo. ¿Elección o pragmatismo por parte de María de Maeztu? La convocatoria de los estudios de Biblioteconomía nos habla de dos realidades simultáneas; por un lado la predilección de María «serán preferidas las personas con un título o matriculadas en un centro oficial», que se tradujo en exigentes programas y exámenes anuales con un limitado número de alumnas aprobadas. ${ }^{26}$ Por otro, la multitud de alumnas sin estas características, que obligó a prever la respuesta a esta realidad «si alguna alumna no estuviera en condiciones de seguir la clase se le advertirá al final de la segunda semana, a fin de que la deje para otro curso, en que haya completado su preparación de cultura general». ${ }^{27}$

El 23 de noviembre de 1934 María de Maeztu, que había dejado su cargo de directora de la Sección de Primaria del Instituto Escuela, comunicó a María Brzezicka de Santullano su propósito de

organizar una cosa cuyo propósito tuve desde la fundación de la Residencia. Esto es, atender a aquellas señoritas que por circunstancias de muy diversa índole han quedado al margen de las tareas escolares durante los años de aprendizaje. ${ }^{28}$

La situación parece haber sido otra en 1932, apogeo cultural de la Residencia, ${ }^{29}$ cuando encontramos entre las matriculadas un considerable y nunca repetido número de alumnas - licenciadas y en menor grado maestras- que eran o habían sido residentes, un 28\% del total. Como hemos señalado, se trató del curso académico con mayor porcentaje de

\footnotetext{
${ }^{24}$ Melián, «En la frontera», 292.

${ }^{25}$ Vázquez Ramil, Mujeres y educación en la España Contemporánea.

${ }^{26}$ Ver referencia 2.

27 «La Enseñanza y los escolares. Curso de Biblioteconomía en la Residencia de Señoritas», $A B C$.

${ }^{28}$ Vázquez Ramil, Mujeres y educación en la España Contemporánea, 216.

${ }^{29}$ Raquel Vázquez Ramil, «La Residencia de Señoritas de Madrid durante la II República: entre la alta cultura y el brillo social», Espacio, Tiempo y Educación 2 (1), (2015): 323-346.
} 
alumnas de grado superior y alumnas con experiencia en trabajos docentes y en bibliotecas. En realidad, este perfil fue una excepción en un colectivo de estudiantes que en conjunto, y más allá de su titulación, presentó desde 1930 a 1935 características que sugieren un decreciente horizonte cultural: descenso de alumnas recomendadas, alumnas con conocimiento de idiomas y alumnas con viajes previos al extranjero. Frente a ellas estos mismos años las alumnas residentes mostraron un incremento absoluto y relativo de universitarias hasta valores entre $61-62 \%$ del total de internas. ${ }^{30}$ Únicamente, y salvando las distancias, el colectivo de opositoras mostró cierto paralelismo en ambos escenarios: mantuvo un crescendo entre las alumnas internas desde el 20\% inicial de 1930-1931 hasta el 27-34-39-30\%, en los cursos posteriores. ${ }^{31} \mathrm{Y}$ en los dos últimos años de Biblioteconomía se perfiló como un grupo de alumnas poseedoras de otros títulos, con notoria ocupación laboral.

Esta mudanza puede interpretarse como reflejo de la evolución en el compromiso de la Residencia con la progresiva incorporación femenina a la vida laboral, que afectó tanto a externas como a internas. Es necesario tener presente que durante la República alcanzaron su plenitud transformaciones sociales y legislativas a favor de la mujer iniciadas a finales del siglo anterior desde unos códigos Civil (1889), Penal (1870) y de Comercio (1885) que restringían totalmente su autonomía. Durante el siglo XIX se crearon las Escuelas de Institutrices (1869), Comercio (1878), Correos y Telégrafos (1883) y, en el primer tercio del siglo xx, aparecieron titulaciones específicamente femeninas como la concedida por la Escuela del Hogar y Profesional de la mujer (1911), la ya referida Escola de Bibliotecàries (1915) o los títulos de Matrona (1904), Enfermería (1915) o Mecanografía (1916). ${ }^{32}$ Tras la llegada al poder en 1923 de Primo de Rivera se emitieron valiosas leyes a favor de las mujeres como fueron la regulación del seguro de maternidad y del trabajo a domicilio, la integración en la educación oficial o la inclusión por primera vez en la vida política. ${ }^{33}$ Centrándonos en la feminización de la profesión bibliotecaria en España, Gloria Nielfa define los estudios de Biblioteconomía

\footnotetext{
${ }^{30}$ Pérez Villanueva, La Residencia de Estudiantes 1910-1936, 604.

31 Vázquez Ramil, Mujeres y educación en la España Contemporánea, 212.

32 Rodríguez Tojas «Mujeres y trabajo: la feminización de la profesión bibliotecaria».

33 Paloma Díaz Fernández «La dictadura de Primo de Rivera. Una oportunidad para la mujer», Espacio, Tiempo y Forma, Serie V, Historia Contemporánea, 17 (2005): 175-190.
} 
como una de las formas de introducirse en este mercado laboral, junto a las oposiciones del Cuerpo Facultativo de Bibliotecarios y Archiveros y/o la formación profesional en la Escola de Bibliotecàries de Cataluña. ${ }^{34}$ Sabemos que en el verano de 1922, dos años antes de solicitar a María de Maeztu residir en la Residencia durante 1925, ${ }^{35}$ María Moliner había aprobado las oposiciones del Cuerpo Facultativo de Archiveros-Bibliotecarios. ${ }^{36}$ Sin embargo el análisis de nuestras alumnas apunta a que la ocupación en bibliotecas fue más causa de inscribirse en los estudios de Biblioteconomía que resultado de hacerlos. De hecho los diplomas para Auxiliares de Bibliotecas nunca alcanzaron categoría oficial, pese a que en 1934 Enriqueta Martín, directora de los mismos, solicitaba a María de Maeztu que requiriera al Ministerio de Educación su reconocimiento. ${ }^{37}$

La deuda hacia el Instituto Nacional de Boston es incontestable. ${ }^{38}$ Esta Institución, fundada por el matrimonio de misioneros norteamericanos William Gulick y Alice Gordon Gulick para favorecer la formación femenina en España, inauguró en 1910 su sede en la calle Miguel Ángel, número 8, de Madrid bajo la dirección de Susan Huntington, para ir ampliando sus programas educativos hasta el bachillerato. En paralelo inició una temprana colaboración con la JAE sobre el internado de niñas del Instituto-Escuela, las clases de inglés, deportes y juegos, hasta terminar alquilando sus locales a la Residencia de Señoritas a partir de 1928. Ese año se fusionaron ambas bibliotecas que según las Memorias de la JAE en el curso 1928-1929 contaban con 14.000 volúmenes y realizaron 18.525 asistencias. ${ }^{39}$ Estas mismas Memorias nos informan de que se abrieron las puertas a alumnas "fueran o no estudiantes oficiales», y de su crecimiento hasta 15.000 volúmenes, cinco bibliotecarias y 25.633 asistencia el curso 1934-1935. ${ }^{40}$ En este escenario el breve curso sobre el sistema Dewey de clasificación impartido en la primavera de 1929 por

\footnotetext{
${ }^{34}$ Rodríguez Tojas «Mujeres y trabajo: la feminización de la profesión bibliotecaria».

35 ARS/Correspondencia María de Maeztu/ Notables/ Carpeta 21, doc.17. El proyecto no llegó a realizarse.

${ }^{36}$ Pilar Rubio López, Vida de María Moliner (Madrid: Eila, 2010).

${ }^{37}$ Los estudios se dividieron en tres cursos, A, B y C, y mientras la asistencia a los dos primeros permitía obtener tras examen un certificado acreditativo, el C fue meramente divulgador.

${ }^{38}$ Carmen de Zulueta, Cien años de educación de la mujer española. Historia del Instituto Internacional (Madrid: Castalia, 1992).

${ }^{39}$ Memorias de la JAE, http://archivojae.edaddeplata.org/jae_app. 346.

${ }^{40}$ Memorias de la JAE, http://archivojae.edaddeplata.org/jae_app. p. 346.
} 
la norteamericana Mauda Polley tuvo tal éxito que el año siguiente se repitió bajo la dirección de Ruth Hill y Enriqueta Martín, para quedar posteriormente a cargo de esta última.

Martín, cuya biografía es aún un proyecto inacabado, llegó a la Residencia en su juventud, y se mantuvo ligada a la misma toda su vida. Durante sus estancias como becaria en el Smith College (cursos 1919-1920) y en el Vasar College (1926) aprendió las normas de clasificación que luego aplicó como responsable de la Biblioteca y los estudios de Biblioteconomía. Trabajo que continuó sin María de Maeztu a partir de 1936, permaneciendo en la Biblioteca de la Residencia de Señoritas, ya como colegio Mayor Teresa de Cepeda, entre 1939 y 1960. Profundamente comprometida con su profesión llegó a escribir, en 1948, un Manual de Bibliotecas con el propósito de servir de libro de texto en los cursos de Biblioteconomía del International Institute de Madrid. ${ }^{41}$

Los documentos conservados sobre el colectivo de Biblioteconomía testimonian otras características no menos relevantes del grupo, por cuanto nos dan idea de su comunión con proyectos educativos de la República. En las Memorias de la JAE de 1931-1932 sobre el curso anterior se hablaba ya de un «ensayo muy modesto de Biblioteca Circulante del que, por haberse organizado muy tarde, no pueden verse aún los resultados», ${ }^{42}$ y en 1932-1933 de la creación de la Asociación Libros para "préstamo de libros a aquellas personas que no tienen posibilidad de procurárselos ni frecuentar bibliotecas», y de las Bibliotecas Populares de la Casa del Niño y de las Bernardas. ${ }^{43}$ Estas actividades no dejaron de ser una proyección para la infancia de las Bibliotecas Circulantes destinadas a colectivos adultos con los que las Misiones Pedagógicas pretendieron transmitir la cultura a las clases sociales más marginadas. ${ }^{44}$ Un objetivo compartido con la promoción de la actividad bibliotecaria que generó la creación de la Junta de Intercambio y Adquisición de Libros para Bibliotecas Públicas a finales de 1931. El fin de esta Junta fue

\footnotetext{
${ }^{41}$ La historia del Instituto Internacional y sus engranajes con la Residencia de Señoritas fue ampliamente investigada en Carmen De Zulueta, Misioneras, feministas, educadoras (Madrid: Castalia, 1984); Zulueta, Cien años de educación de la mujer española.

${ }^{42}$ Memorias de la JAE, http://archivojae.edaddeplata.org/jae_app., pp. 345-346.

${ }^{43}$ Si bien sólo he encontrado una referencia a esta última en las memorias de la JAE 1933-1934.

${ }^{44}$ Pilar Faus Sevilla, La lectura pública en España (Madrid: Anabad, 1990), 33-53.
} 
establecer, promocionar y financiar las bibliotecas que se había ordenado instituir en todas las Escuelas Nacionales en decreto de dos meses atrás. ${ }^{45}$ La voz de Elena Fortún en cartas, crónicas periodísticas, ${ }^{46}$ y en boca de su alter-ego Celia adquiere aquí un papel esencial para acercarnos a la ideología de sus promotoras, más allá de las enunciaciones académicas,

Ten en cuenta que la educación y la cultura moldean el cerebro y la dan una moral [...] Esas pobres gentes, golpeadas y maltratadas por una sociedad que les niega todo, devuelvan mal por mal [...] ¡serían ángeles si no lo hicieran! [...] Papá me explicó una tarde que él defendía al pueblo para que se educara en el mismo banco de la escuela que el hijo del médico y del millonario y que no hubiera más diferencias entre ellos que las limitaciones de la naturaleza [...] lo primero es ser libre y hacer lo que se quiere. ${ }^{47}$

Elena formó parte de un grupo de mujeres "pre-modernas» ${ }^{48}$ nacidas entre 1883 y 1887 que, tras una juventud y primera madurez en el anonimato, iniciaron su vida pública de la mano de familiares — por nacimiento o matrimonio- de prestigio en el mundo cultural de la época. Bajo el influjo mixto de la ILE y el espíritu del Centro de Estudios Históricos de Menéndez Pidal, este colectivo mostró un interés especial por promover la educación de la infancia y recuperar el papel femenino en la «intrahistoria» mediante la recuperación del folklore y la tradición. ${ }^{49}$ La Casa del Niño se gestó y financió por la Sección Social del Lyceum Club en 1929, como una guardería infantil gratuita para madres obreras localizada en un local de Cuatro Caminos. ${ }^{50}$ En el desarrollo de esta pionera iniciativa liderada por María de Maeztu encontramos otras mujeres de perfil similar a Elena Fortún como Carmen Baroja o María Martos de Baeza, quien se inscribió en los estudios de Biblioteconomía

\footnotetext{
${ }^{45}$ Faus Sevilla, La lectura pública, 60.

${ }^{46}$ Elena Fortún y Matilde Ras, El camino es nuestro (Madrid: Fundación Banco de Santander, 2014).

${ }^{47}$ Elena Fortún, Celia en la revolución, 51.

${ }^{48}$ Shirley Mangini, Las modernas de Madrid (Barcelona: Península, 2000).

${ }^{49}$ Melián, «Memorias de la Penumbra».

${ }^{50}$ Amparo Hurtado «El Lyceum Club Femenino (Madrid 1926-1939)», Boletín Institución Libre de Enseñanza, 36 (1999): 23-35.
} 
el curso 1930-1931. ${ }^{51}$ En 1926 Elena escribía a su amiga Mercedes Hernández diciéndole:

con lo del Club estoy encantada; creo que se va a hacer una verdadera labor social a favor de la mujer y del niño. Somos ya muchísimas. Yo pertenezco a la Sección de Sociología, y pienso que mis ciegos van a ganar mucho con ello. ${ }^{52}$

Años más tarde acudirían a esta Casa del Niño las alumnas de Biblioteconomía para narrarles cuentos los domingos por la tarde, en que no se abría como guardería. Elena, que fue la encargada de dirigir la Clase de Narradoras de Cuentos para las alumnas de segundo año, ${ }^{53}$ elogió públicamente la dedicación de unas jóvenes que — cuando el edificio estaba en obras- atendían a los niños al aire libre esperándolos en la puerta con los libros bajo su umbral. ${ }^{54}$

La revista Crónica publicó en 1935 una emotiva evocación de la autora sobre esta empresa,

La tierra cruje helada y "La casa del niño», aterida por fuera, es por dentro un corazón caliente que late con el gorjeo de setenta pequeñitos de 2 a 5 años, desde las 8 de la mañana hasta las 7 de la tarde. ¡Dios mío! hoy es Nochebuena, y aquí hay 70 niños bien abrigados y alimentados, limpios y felices, lejos por muchas horas del hambre y del dolor [...]. Gracias a su maravillosa administración puede sostenerse esta obra con suscripciones. Pero hacen falta muchas casitas como esta. Una, por lo menos, en cada distrito iqué es una sola guardería de niños en todo Madrid! [...]. Saben mucho de cuentos los niños de la casita. Un grupo de narradoras de cuentos los visita todas las semanas y deja en sus almas tersas y blancas las primeras emocionadas aventuras. ${ }^{55}$

\footnotetext{
${ }^{51}$ Elvira M. Melián, «Rastros de nube, María Martos de Baeza y su mundo», Arenal, 8 (2), (2001), 379-388.

${ }^{52}$ Dorado, Los mil sueños de Elena Fortún, 86.

${ }^{53}$ Elena Fortún, El arte de contar cuentos a los niños (Buenos Aires: Instituto Cultural Joaquín V, González, 1947).

${ }^{54}$ Fraga Fernández, Elena Fortún, periodista, 195.

${ }^{55}$ Elena Fortún, «Nochebuena en la Casa del Niño» Crónica Ext Nav, 1935.
} 
Las Bibliotecas Infantiles del Lyceum emularon la «Hora del cuento semanal», iniciativa desarrollada en Francia por la comunidad estadounidense, de las que Elena obtuvo información visitándolas en París. Para ella, que en la ficha de inscripción a los estudios de Biblioteconomía se describió como "profesional del cuento para niños», éste poseía grandes potenciales para «estimular la atención, la imaginación, crear el lenguaje, favorecer la inquietud literaria y establecer una base moral». ${ }^{56}$ Pero además, en su condición de «mujer del 98», ${ }^{57}$ lo consideraba un exponente esencial del espíritu de los pueblos «es muy posible que todo cuento encierre en símbolos algo que ya se ha olvidado quedando únicamente su bella envoltura, pues el símbolo es la forma primitiva de las manifestaciones del espíritu». ${ }^{58}$

El cuento era la forma de llegar a la infancia y formar personas morales y buenas, una idea que nos retrotrae directamente a la idiosincrasia krausista,

Todo niño desea, como todos deseamos, ahorrarse experiencias, saber cómo han vivido otros, cómo han triunfado y cómo han fracasado, cómo se consigue lo que se desea y cómo y por qué se pierde después de conseguido [...] es el cuento lo que le da la gran riqueza de ejemplos de honradez y bondad más al alcance y más a tono con sus pueriles medios de comprensión. ${ }^{59}$

Según la autora el éxito de esta actividad pedagógica llevó en 1935 a la Normal de Madrid a considerar la obligatoriedad de «la asignatura de Narración de Cuentos», proyecto que no vio la luz por los acontecimientos históricos,

Nuestra labor, comenzada en el año 33, se vio interrumpida por la Revolución, en la que algunas de mis discípulas murieron. Las demás quedamos diseminadas por el mundo, en condición tan desvinculada ya del pasado y con tan desoladoras dificultades, que no he podido localizar a ninguna de las muchachas que comenzaron conmigo aquél trabajo. ${ }^{60}$

\footnotetext{
${ }^{56}$ Elena Fortún, Canciones infantiles populares (Madrid: Aguilar, 1953).

${ }^{57}$ Carmen Baroja, Recuerdos de una mujer de la generación del 98 (Barcelona: Tusquets, 1998).

${ }^{58}$ Fortún, El arte de contar cuentos a los niños, 30.

${ }^{59}$ Fortún, El arte de contar cuentos a los niños, 33.

${ }^{60}$ Fortún, El arte de contar cuentos a los niños, 25.
} 
Elena Fortún trabajó durante su exilio bonaerense como bibliotecaria en la Biblioteca Municipal de Buenos Aires. Fueron años de soledad y refugio en el exilio interior, donde el trabajo fue su fuente de resistencia, como escribía a su íntima amiga Matilde Ras. ${ }^{61}$ Como en otros muchos aspectos de su idiosincrasia la pasión por la Biblioteconomía quedó reflejada en su literatura. Sus artículos periodísticos en la revista Crónica con frecuencia abordaron temas relacionados con la educación y las Bibliotecas Infantiles. ${ }^{62}$ Y llegó a iniciar el libro Celia Bibliotecaria, que nunca llegó a desarrollar, y de cuya existencia sabemos gracias a Nuria Capdevila-Argüelles. ${ }^{63}$ En febrero de 1951 escribía desde Barcelona a su amiga Carmen Laforet sobre el libro Patita y Mila, estudiantes, que estaba finalizando. Este volumen, que cerraría la serie Celia, contiene un capítulo sobre el aprendizaje de la catalogación. ${ }^{64}$

\section{CONTRA EL OLVIDO}

Muchas intelectuales del primer tercio del siglo xx sustentaron con sus afanes y luchas el progreso que significó para las mujeres el esfuerzo pedagógico de la Residencia de Señoritas. ${ }^{65}$ Elena Fortún ha pasado a la pequeña historia de la cultura española; no así la mayoría de las participantes de unos estudios hoy olvidados, enmarcados entre las numerosas

\footnotetext{
${ }^{61}$ Matilde Ras, Diario (Madrid: Instituto Editorial Reus, 1949), 129: «Continúo en mi oficina, que se lleva lo mejor del día y de mi vida. Trabajo y trabajo sin descanso en papeles oficinescos que me ha costado un triunfo entender, porque mi cerebro se negaba a dejar entrar semejantes absurdos. Al fin, lo entendí ¿creerás que estoy contenta? Es tal vez el mayor triunfo sobre mi misma que he tenido en mi vida, entender un Registro Civil y saber desempeñar sus funciones ipero qué esfuerzo para vencerme! He llorado mucho, me he agotado en un constante dudar, en la indecisión de abandonarlo todo o dejarme llevar por la vida».

${ }^{62}$ Elena Fortún, «Los pioneros también organizan Residencias Infantiles»; «La Caseta. Biblioteca Infantil inaugurada por la Federación Nacional de Pioneros, y que ofrece a los niños valencianos y a los pequeños forasteros residentes en Valencia cuatrocientos volúmenes de literatura y de estampas amenas e instructivas»; «La Guardería Infantil del Instituto-Escuela»; «Cómo se trabaja en los Grupos Escolares de Madrid», Crónica (Madrid) 1 de agosto de 1937, 13 de septiembre de 1936, 23 de agosto de 1936; y 30 de octubre de 1938, respectivamente. Sobre la labor periodística de Elena Fortún consultar Fraga Fernández, Elena Fortún, periodista.

${ }^{63}$ Carmen Laforet \& Elena Fortún, De corazón y Alma (1947-1952) (Madrid: Fundación Banco de Santander, 2017), 24.

${ }^{64}$ Elena Fortún, Patita y Mila, estudiantes (Madrid: Aguilar,1882).

${ }^{65}$ Álvaro Ribagorda, «Una historia en la penumbra: las intelectuales de la Residencia de Señoritas» Sistema 188 (2005): 54-61.
} 
iniciativas lideradas por la JAE para la promoción educativa femenina. ${ }^{66}$ Unos estudios con alto nivel de exigencia y de carácter eminentemente práctico, como práctica fue su adalid, orientados a la promoción laboral y cultural de mujeres carentes de otros cauces académicos.

En este trabajo se ha intentado acercar el perfil colectivo de las alumnas de Biblioteconomía, y enmarcarlo en unas coordenadas históricas que las hicieron partícipes del credo krausista-gineriano de la ILE en general, y de la JAE en particular: educar como medio para formar seres humanos «altruistas y entusiastas por lo noble y fortalecidos por el dominio de lo corporal y lo espiritual». ${ }^{67}$

Algunas alumnas, aquí enumeradas, dejaron huellas que posiblemente permitan recuperar su biografía más allá de este esbozo; otras únicamente un nombre y unos apellidos, destinados previsiblemente al olvido. Acaso la mejor manera de honrar su memoria sea terminar reproduciendo la respuesta de otra anónima estudiante de Coro y Música, a la primera pregunta del examen de junio de 1935:

¿Es o no importante el estudio de la música, aún para aquellas personas que no la estudien profesionalmente?

Sí, es importante el estudio de la música, aún para los que no la estudien profesionalmente, pues al estudiarla se capacita a la persona para recibir un deleite espiritual más hondo, que le está vedado al que no tiene estos conocimientos, aun cuando tenga sensibilidad. ${ }^{68}$

Basta con sustituir la palabra música por la palabra literatura. O libro.

\footnotetext{
${ }^{66}$ Teresa Marín Eced, La renovación pedagógica en España (1907-1936). Los pensionados en pedagogía por la Junta de Ampliación de Estudios (Madrid: Consejo Superior de Investigaciones Científicas, 1989); Teresa Marín Eced, Innovadores de la educación en España (Becarios de la JAE) (Castilla-La Mancha, Universidad de Castilla-La Mancha, 1991).

${ }^{67}$ Vicente Cacho Viu, La institución Libre de Enseñanza, I (orígenes y etapa universitaria) (Madrid: Rialp, 1962); Antonio Jiménez Landi, La Institución Libre de Enseñanza y su ambiente (Madrid: Editorial Complutense, 1996).

${ }^{68}$ ARS, Estudios de Coro y Música, exámenes, caja12/ carpeta7/ 89.
} 


\section{Nota sobre la autora}

Elvira M. Melián es doctora en Medicina y Cirugía por la Universidad Autónoma de Madrid y especialista en Endocrinología y Nutrición. En la actualidad trabaja en un Hospital de Madrid, ciudad en la que reside. Además de su labor sanitaria ha realizado un Máster en Ciencias Históricas en la Universidad Rey Juan Carlos, y publicado en revistas especializadas numerosos trabajos sobre la «intrahistoria» femenina de la España Moderna y Contemporánea. Proyección de su quehacer literario e investigador durante el primer tercio del siglo xx, especialmente la Segunda República, son sus estudios sobre la notable y minimizada presencia de la mujer en la Institución Libre de Enseñanza, entre los que se engloba el presente artículo, o el libro Para los que no vieron (La Coruña: Do Castro, 2006), en memoria de Francisco Lamas, médico e intelectual represaliado, que fuera el último alcalde republicano en Lugo antes de la Guerra Civil.

\section{Referencias}

BAROJA, Carmen. Recuerdos de una mujer de la generación del 98. Barcelona: Tusquets, 1998.

CACHO VIU, Vicente. La institución Libre de Enseñanza, I (orígenes y etapa universitaria). Madrid: Rialp, 1962.

Codina CAnEt, María Adelina. «Fuentes Documentales y Archivos de la Residencia de Señoritas de Madrid (1915-1936)». Revista General de Información y Documentación 25 (2), (2015): 493-515.

Díaz Fernández, Paloma. "La dictadura de Primo de Rivera. Una oportunidad para la mujer». Espacio, Tiempo y Forma, Serie V, Historia Contemporánea, 17 (2005): 175-190.

Dorao, Marisol. Los mil sueños de Elena Fortún. Cádiz: Universidad de Cádiz, 1999.

Faus Sevilla, Pilar. La lectura pública en España. Madrid: Anabad, 1990.

ForTún, Elena. El arte de contar cuentos a los niños. Buenos Aires: Instituto Cultural Joaquín V. González, 1947.

- Canciones infantiles populares. Madrid: Aguilar, 1953.

- Patita y Mila, estudiantes. Madrid: Aguilar,1982.

- Celia en la Revolución. Madrid: Aguilar, 1987.

ForTún, Elena y Matilde RAs. El camino es nuestro. Madrid: Fundación Banco de Santander, 2014. 
Fraga Fernández, María Jesús. Elena Fortún, periodista. Madrid: Pliegos, 2013. Hurtado, Amparo. «El Lyceum Club Femenino (Madrid 1926-1939)». Boletín Institución Libre de Enseñanza 36 (1999): 23-35.

JiménEz LANDI, Antonio. La Institución Libre de Enseñanza y su ambiente. Madrid: Editorial Complutense, 1996.

LAFORET, Carmen y Elena ForTún. De corazón y Alma (1947-1952). Madrid: Fundación Banco de Santander, 2017.

Mangini, Shirley. Las modernas de Madrid. Barcelona: Península, 2000.

MARín EcED, Teresa. La renovación pedagógica en España (1907-1936). Los pensionados en pedagogía por la Junta de Ampliación de Estudios. Madrid: Consejo Superior de Investigaciones Científicas, 1989.

- Innovadores de la educación en España (Becarios de la JAE). Castilla-La Mancha: Universidad de Castilla-La Mancha, 1991.

Melián, Elvira M. «Rastros de nube, María Martos de Baeza y su mundo» Arenal 8 (2), (2001): 379-388.

- «Memorias de la Penumbra: Carmen Baroja, Zenobia Camprubí y Elena Fortún, mujeres en la penumbra del 98». Boletín Institución Libre de Enseñanza, 5 (2005): 19-39.

- «María de Maeztu Withney y Sofía Novoa Ortiz (1919-1936), cultivar la salud, cultivar el espíritu, cultivar la lealtad». Circunstancia: Revista de Ciencias Sociales del Instituto Universitario de Investigación Ortega y Gasset 14 (2007). www.fog.es/circunstancia/numero14/art7.

- «En la frontera: señas de identidad de la labor pedagógica hispano-americanista en María de Maeztu (1924-1936)». Historia de la Educación 34 (2015): 287-303.

PÉREz-VILlanueva Tovar, Isabel. María de Maeztu: una mujer en el reformismo educativo español. Madrid: UNED, 1989.

- La Residencia de Estudiantes 1910-1936. Grupo Universitario y Residencia de Señoritas. Madrid: CSIC, 2011.

RAS, Matilde. Diario. Madrid: Instituto Editorial Reus, 1949.

RIBAgORDA, Álvaro. "Una historia en la penumbra: las intelectuales de la Residencia de Señoritas» Sistema 188 (2005): 54-61.

Rodríguez TOJAS, Alba. «Mujeres y trabajo: la feminización de la profesión bibliotecaria». PhD diss., Universidad Complutense de Madrid, 2013.

https://www.ucm.es/data/cont/docs/329-2013-12-17-.

Rubio López, Pilar. Vida de María Moliner. Madrid: Eila, 2010.

VÁzQuez RAmiL, Raquel. Mujeres y educación en la España Contemporánea. La Institución Libre de Enseñanza y la Residencia de Señoritas de Madrid. Madrid: Akal, 2012. 
- «La Residencia de Señoritas de Madrid durante la II República: entre la alta cultura y el brillo social». Espacio, Tiempo y Educación 2 (1), (2015): 323-346.

VV. AA. Las Misiones Pedagógicas 1931-1936. Madrid: Residencia de Estudiantes, 2007.

Zulueta, Carmen de. Misioneras, feministas, educadoras. Madrid: Castalia, 1984.

- Cien años de educación de la mujer española. Historia del Instituto Internacional. Madrid: Castalia, 1992.

Zulueta, Carmen de y Alicia Moreno. Ni convento ni college. La Residencia de Señoritas. Madrid: Consejo Superior de Investigaciones Científicas, 1993.

\section{Anexo 1. Ficha de Elena Fortún}

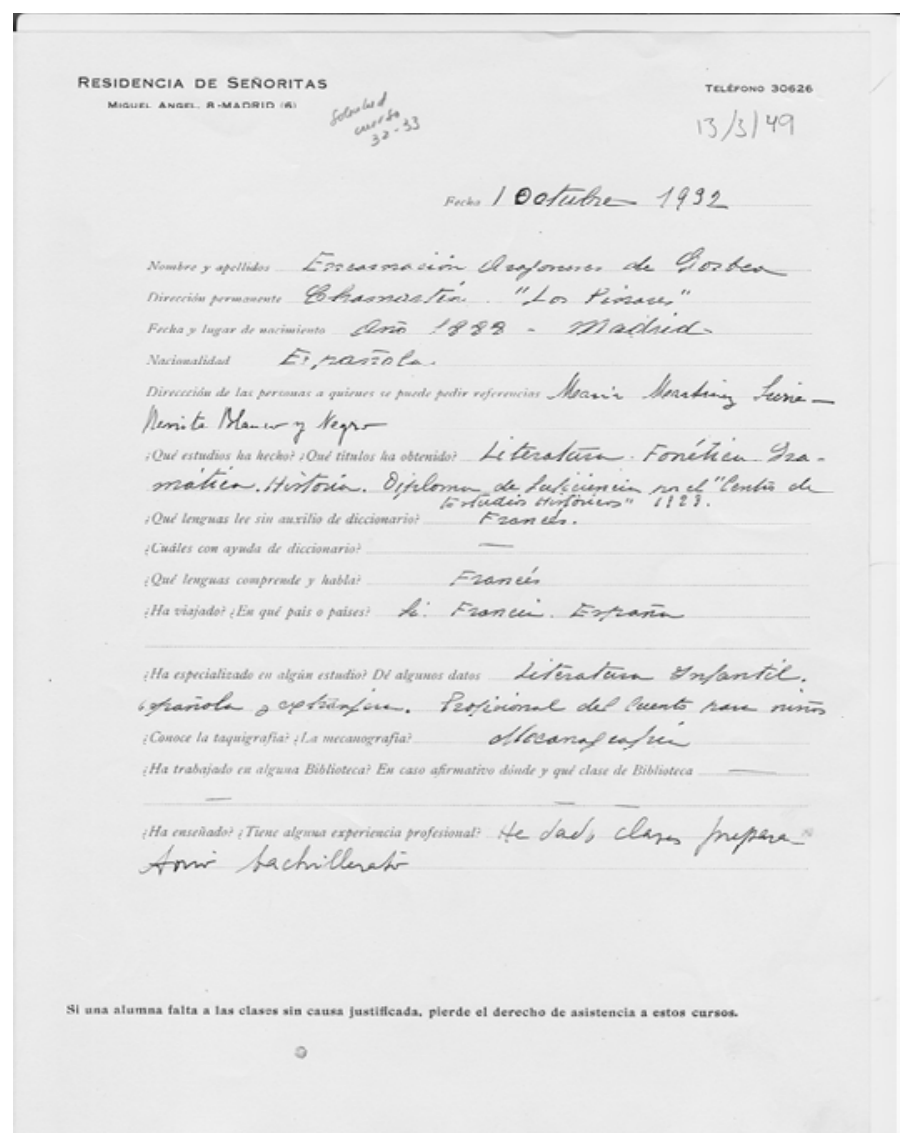

